\title{
ERCC1 and XPF expression in human testicular germ cell tumors
}

\author{
BEATE KÖBERLE $^{1^{*}}$, WALBURGIS BRENNER $^{2^{*}}$, ANDREAS ALBERS $^{3}$, \\ SVETLANA USANOVA ${ }^{1}$, JOACHIM W. THÜROFF ${ }^{2}$ and BERND KAINA ${ }^{1}$ \\ ${ }^{1}$ Institute of Toxicology and ${ }^{2}$ Department of Urology, University Medical Center Mainz, Mainz; \\ ${ }^{3}$ Department of Otorhinolaryngology and Head and Neck Surgery, Charité-University \\ Medical Center Berlin, Berlin, Germany
}

Received August 28, 2009; Accepted October 8, 2009

DOI: 10.3892/or_00000627

\begin{abstract}
Nucleotide excision repair (NER) is one of the factors influencing the cellular sensitivity to anticancer drugs. In the present study we compared the expression of the NER proteins ERCC1 and XPF in 24 testicular germ cell tumors (TGCT) with the corresponding normal testicular tissue of the same patient. Using immunoblotting, we demonstrated in TGCT a significant increase of ERCC1 expression compared to the normal tissue. There was no significant increase in XPF expression in TCGT. Based on histological characteristics TGCT are subgrouped into seminomas and non-seminomas, the latter being clinically more aggressive. Investigating ERCC1 levels in seminomas we found a slightly increased expression compared to normal tissue, which was, however, not significant. Similarly, no significant difference was observed for XPF levels in seminomas compared to normal testis tissue. In non-seminomas, however, we found a significant increase in the expression of ERCC1 $(\mathrm{p}<0.017)$ and XPF $(\mathrm{p}<0.03)$ when compared with the corresponding normal tissue. Comparing seminomas with non-seminomas, we observed a significant increase in the expression of ERCC1 $(p<0.05)$ and XPF $(p<0.007)$ in the non-seminomas. Furthermore, a correlation between the expression of ERCC1 and XPF was observed. Our data demonstrate that non-seminomas are characterized by an increased expression of ERCC1 and XPF protein compared to seminomas and the normal testis tissue. The data indicate a possible up-regulation of ERCC1 and XPF during TGCT progression.
\end{abstract}

Correspondence to: Dr Beate Köberle, Institute of Toxicology, University Medical Center Mainz, Obere Zahlbacher Strasse 67, D-55131 Mainz, Germany

E-mail: koeberle@uni-mainz.de

${ }^{*}$ Contributed equally

Key words: non-seminomas, seminomas, nucleotide excision repair, protein overexpression, testis tumor development

\section{Introduction}

Testicular germ cell tumors (TGCT) are relatively rare, accounting for less than $1 \%$ of all male malignancies. However, they are the most common solid malignant tumors in men 20-40 years of age $(1,2)$. TGCT are a heterogeneous group of neoplasms derived from the germ cell lineage (3). Histologically TGCT can be divided into seminomas and non-seminomas, and the latter is further subdivided into yolk sac carcinoma, embryonal carcinoma, teratoma and choriocarcinoma $(4,5)$. Seminomas are composed of uniform cells, non-seminomas contain one or more histological subtypes. It is generally accepted that both types arise from a common progenitor, named carcinoma in situ. At the time of diagnosis about $25 \%$ of seminoma and about $60 \%$ of non-seminoma patients suffer from metastatic disease. Remarkable progress has been made in the medical treatment of advanced TGCT. Whilst seminomas can be cured by dissection and radiation therapy, non-seminomas require chemotherapy, with cisplatin being the gold standard. Using cisplatin-based combination chemotherapy even more than $80 \%$ of patients with metastatic TGCT can be cured $(6,7)$. This is in stark contrast to the often poor therapeutic response in most other solid tumors (8). The molecular basis for the extreme sensitivity of TGCT to cisplatin-based chemotherapy remains poorly understood (9).

DNA repair is one of the factors influencing the cellular sensitivity/resistance towards cisplatin (10). Nucleotide excision repair (NER) and interstrand crosslink (ICL) repair play a central role in the repair of cisplatin-induced DNA intrastrand adducts and interstrand crosslinks $(11,12)$. The DNA repair protein ERCC1 associates with the xeroderma pigmentosum group $\mathrm{F}$ (XPF) protein to form a nuclease that functions in NER and ICL repair $(13,14)$. In cells in vitro, ERCC1 expression has been shown to be associated with resistance to cisplatin. This prompted investigations as to the influence of ERCC1 on resistance of tumors to cisplatin chemotherapy, and it was shown that in tumor tissues of patients with cancer of the lung, head, neck and ovary high levels of ERCC1 mRNA or protein correlate with a poor response towards cisplatin-based chemotherapy (15-20). Collectively the data suggest that the ERCC1 expression level is a useful marker of tumor cell resistance to cisplatin and its analogs. 
Table I. Tumor characteristics of patients included into the present study.

\begin{tabular}{lccc}
\hline & $\begin{array}{c}\text { Seminoma } \\
(\mathrm{n}=16)\end{array}$ & $\begin{array}{c}\text { Non-seminoma } \\
(\mathrm{n}=8)\end{array}$ & $\begin{array}{c}\text { All } \\
(\mathrm{n}=24)\end{array}$ \\
\hline Median age (years) & $34(25-47)$ & $34(26-44)$ & $34(25-47)$ \\
Tumor size $(\mathrm{cm})$ & $4.7(2.0-7.5)$ & $3.0(1.6-5.5)$ & $4.5(1.6-7.5)$ \\
pT1 & 9 & 2 & 11 \\
pT2 & 7 & 6 & 13 \\
Median follow-up time & $105(46-124)$ & $71(36-106)$ & $103(36-124)$ \\
(months) & & & \\
\hline
\end{tabular}

Using in vitro models, it has been shown that testis tumor cell lines are characterized by reduced levels of ERCC1 and XPF compared to cell lines derived from other types of cancer (21). However, to date no data are available on the expression of ERCC1 and XPF in testicular tumors, although as mentioned above for non-seminomas cisplatin belongs to first-line therapy. Therefore, we aimed at investigating the expression level of ERCC1 and XPF in testicular germ cell tumors (TGCT) and compared it with the corresponding normal testicular tissue of the same patient. We also compared the expression of ERCC1 and XPF in seminomas versus nonseminomas and investigated whether the expression levels of ERCC1 and XPF proteins are correlated. Finally we asked whether there is a correlation between ERCC1 and XPF and clinical parameters such as tumor size and TNM stage. Our data show that ERCC1 and XPF are up-regulated in nonseminoma TGCT.

\section{Materials and methods}

Patients and specimens. Tissue samples were obtained under sterile conditions from 24 patients with primary testis tumors who underwent orchiectomies at our Department between 1998 and 2002. Samples from testis and tumor tissue $(\sim 5 \times 5 \times 5 \mathrm{~mm})$ were shock-frozen in liquid nitrogen and stored at $-80^{\circ} \mathrm{C}$. The diagnosis of seminoma or non-seminoma was based on hematoxylin and eosin sections. Patient specific data are listed in Table I.

Cell lines. Origins of the $833 \mathrm{~K}$ human TGCT cell line and MGH-U1 human bladder cancer cell line were described previously $(22,23)$. The cell lines were grown in RPMI-1640 medium supplemented with $10 \%$ heat-inactivated fetal calf serum, L-glutamine (PAA) and 5\% antibiotics (penicillin/ streptavidin). Cells were cultivated at $37^{\circ} \mathrm{C}$ in a humidified atmosphere of $5 \% \mathrm{CO}_{2}$ in air.

Preparation of tissue extracts. Deeply frozen testis tissue was homogenized in buffer containing $20 \mathrm{mM}$ Tris- $\mathrm{HCl}(\mathrm{pH} \mathrm{8.5)}$, $1 \mathrm{mM}$ EDTA, $1 \mathrm{mM} 3$ mercaptoethanol, 5\% glycerol and protease inhibitors $(10 \mu \mathrm{g} / \mathrm{ml}$ aptotinin, $10 \mathrm{mM}$ bestatin, $10 \mathrm{mM}$ leupeptin, $1 \mathrm{mM}$ pepstatin and $0.1 \mathrm{mM}$ PMSF) using an Ultra Turrax homogenizer. After homogenization the lysate was centrifuged to remove debris. The supernatant was snapfrozen in liquid nitrogen and stored at $-80^{\circ} \mathrm{C}$. The protein concentration of the supernatant was determined by the Bradford method using RotiQuant reagent (Roth).

Immunoblotting for ERCC1 and XPF proteins. For immunoblotting, $50 \mu \mathrm{g}$ extract protein were separated by electrophoresis on SDS $10 \%$ polyacrylamide gels. Protein $(50 \mu \mathrm{g})$ of MGH-U1 bladder cancer cells and $833 \mathrm{~K}$ testis tumor cell were run on each blot to allow for comparison between independent blots. Proteins were transferred to Whatman nitrocellulose membrane (Roth) overnight in Tris-glycine buffer (25 mM Tris-HCl, $192 \mathrm{mM}$ glycine, 20\% methanol) in a Bio-Rad Mini-Protean 3 Electrophoresis Cell at a constant voltage of $30 \mathrm{~V}$. Primary antibodies used were as follows: XPF 1/5000 dilution of polyclonal antibody RA1 raised against residues 571-905 of human XPF protein (24); ERCC1 1/1000 dilution of monoclonal antibody 3H11 (Neomarkers); RPA 1/5000 dilution of monoclonal antibody 9H8 (Neomarkers). Membranes were incubated with the primary antibody overnight at $4^{\circ} \mathrm{C}$, followed by incubation for $1 \mathrm{~h}$ with either $1 / 2000$ peroxidase-labeled anti-rabbit $\mathrm{IgG}$ or $1 / 5000$ dilution of peroxidase-labeled anti-mouse $\mathrm{IgG}$ (Dako). Proteins were visualized by chemiluminescence using a solution consisting of $0.1 \mathrm{M}$ Tris $\mathrm{HCl} \mathrm{pH} \mathrm{8.6,0.25}$ $\mathrm{mg} / \mathrm{ml}$ luminol, $0.1 \mathrm{mg} / \mathrm{ml}$ hydrocoumarine acid, $0.01 \%$ $\mathrm{H}_{2} \mathrm{O}_{2}$. For quantification of the protein signals SynGene software was used. The expression levels of ERCC1 and XPF were normalized to RPA protein expression. RPA was chosen because it is a nuclear protein involved in several housekeeping aspects of DNA metabolism, and there was relatively little variation in RPA for cell lines from different tumor types (21).

Statistical analysis. For statistical analyses SPSS 17.0 software was applied. The expression of ERCC1 and XPF in testis cancer tissue and the corresponding testis tissue was quantified and presented as relative units. Differences in the expression in testis tissue and tumor tissue was calculated by Wilcoxon test. Differences in the expression of seminomas versus nonseminomas or in dependence of histophathological parameters were calculated by Mann-Whitney U test. Differences were considered statistically significant at $p<0.05$. A correlation between the expression of ERCC1 and XPF was determined and the linear regression $\left(\mathrm{R}^{2}\right.$ linear) was calculated. 


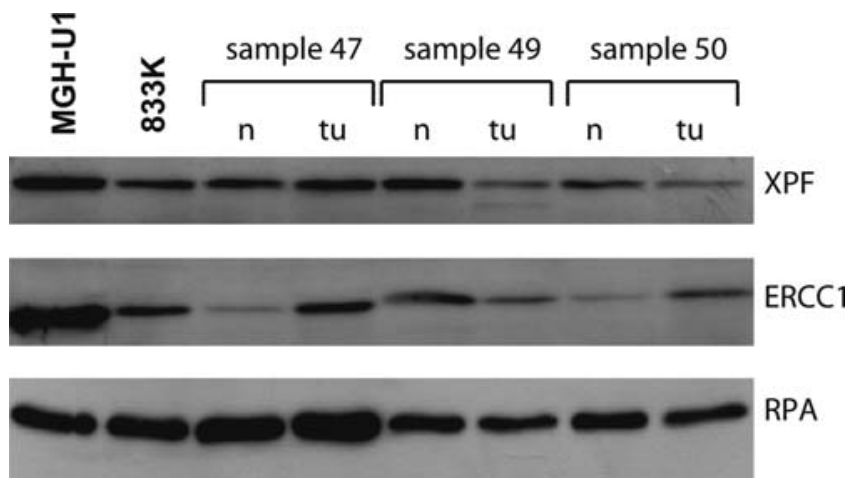

Figure 1. Immunoblot analysis of XPF and ERCC1 proteins in extracts of the bladder cancer cell line MGH-U1, the testis tumor cell line $833 \mathrm{~K}$ and in tumor tissue (tu) and corresponding tissue (n) of three patients. RPA was used as a loading control.
A

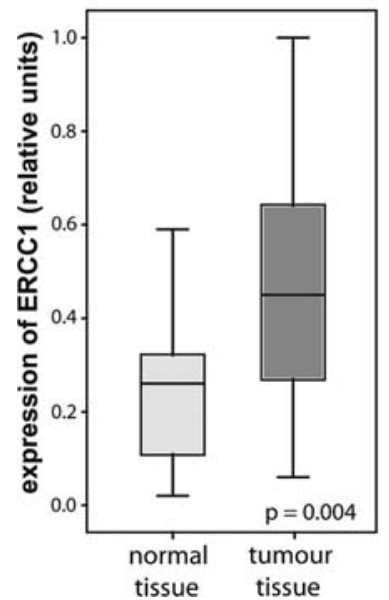

B

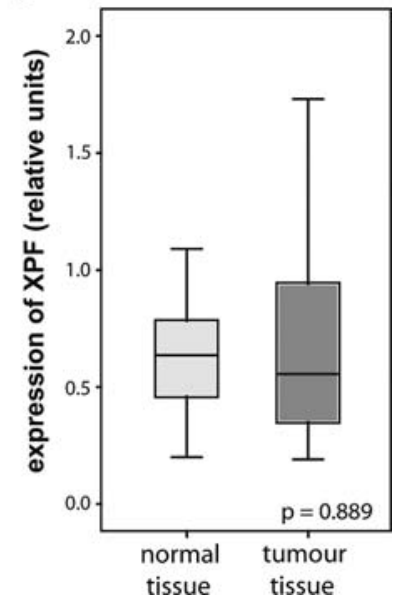

Figure 2. Expression of ERCC1 (A) and XPF (B) in testis tumor and the corresponding normal testis tissue determined by immunoblot analysis. The values represent the amount of antigen determined by computer-aided quantification of the bands. Box plots show medians (central lane), 25 and 75 percentiles (lower and upper side of the box) and minimum and maximum (lower and upper bars). Extreme values have been excluded from the graph.

\section{Results}

Using quantitative immunoblotting, we investigated the expression of ERCC1 and XPF protein in 24 testis tumors and their corresponding normal testicular tissues. Examples of a representative immunoblot are shown in Fig. 1. Normalizing to RPA, we found a significant difference $(\mathrm{p}<0.004)$ in the expression of ERCC1 in tumor compared to the normal tissue. The relative ERCC1 expression increased from 0.26 to 0.45 (Fig. 2). For XPF protein no significant difference in the expression level in tumor versus normal tissue was detected.

Of the 24 tumors examined 16 samples were seminomas and 8 samples were non-seminomas. We therefore investigated whether there is a difference in the expression of ERCC1 and XPF with respect to testis tumor subtype. We found no significant difference in expression levels of ERCC1
A $\square$ normal tissue

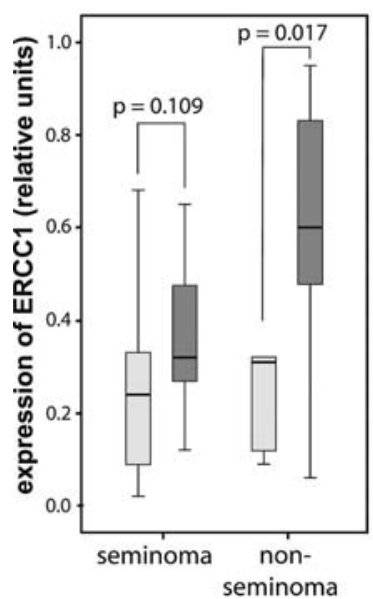

B
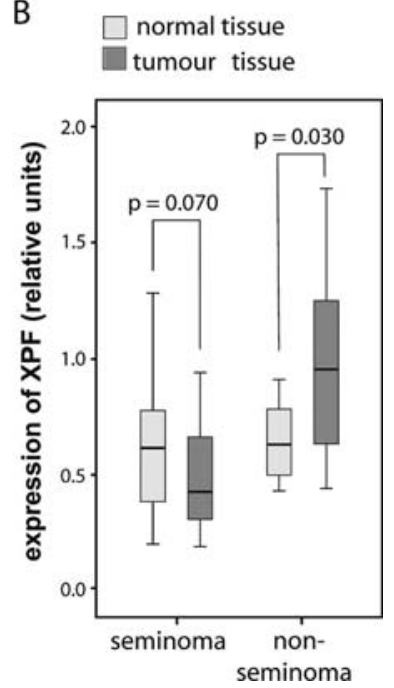

Figure 3. Expression of ERCC1 (A) and XPF (B) in testis tumor tissues (seminomas, non-seminomas) and the corresponding testis tissue, as determined by immunoblot analysis. The values represent the amount of antigen determined by computer-aided quantification of the bands. Box plots show medians (central lane), 25 and 75 percentiles (lower and upper side of the box) and minimum and maximum (lower and upper bars). Extreme values have been excluded from the graph.
A

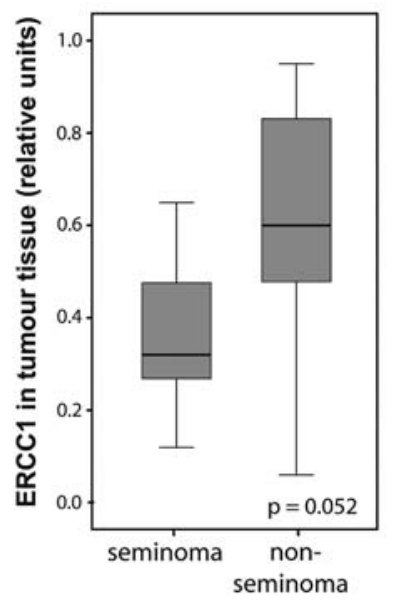

B

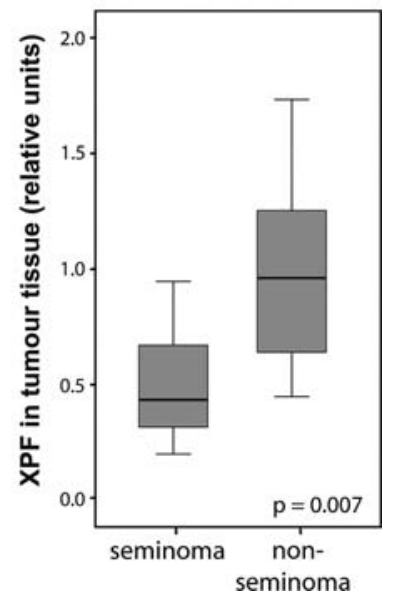

Figure 4. Expression of ERCC1 (A) and XPF (B) in seminomas compared with non-seminomas, as determined by immunoblot analysis. The values represent the amount of antigen determined by computer-aided quantification of the bands. Box plots show medians (central lane), 25 and 75 percentiles (lower and upper side of the box) and minimum and maximum (lower and upper bars). Extreme values have been excluded from the graph.

in seminoma when compared to normal corresponding testis tissue (Fig. 3A). However, the ERCC1 protein expression was significantly increased (by $\sim 2$-fold) in non-seminoma compared to normal tissue $(\mathrm{p}<0.017)$. Similarly, no significant difference was found in expression levels of XPF when comparing seminoma with normal testis tissue (Fig. 3B). In non-seminoma XPF protein was significantly ameliorated in the tumor compared to normal tissue $(\mathrm{p}<0.03)$. When we 


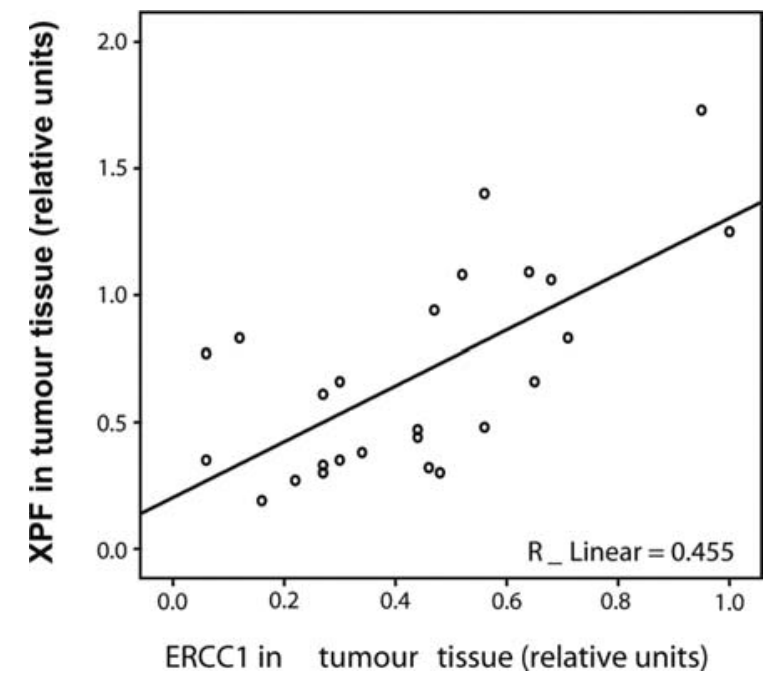

Figure 5. Correlation between the expression level of ERCC1 and XPF in testis tumor tissue. Expression values were determined by immunoblot analysis and computer-aided quantification. The expression of ERCC1 correlated with the expression of XPF $\left(\mathrm{R}^{2}\right.$ linear $\left.=0.455\right)$.

compared ERCC1 and XPF levels in seminomas with nonseminomas we found significantly higher levels for ERCC1 $(\mathrm{p}<0.05)$ and XPF $(\mathrm{p}<0.007)$ in the non-seminoma tumor tissues (Fig. 4).

We also attempted to correlate the expression levels of ERCC1 and XPF in testis tissues with clinical parameters, including tumor size and TNM stage. We found no correlation between tumor size and ERCC1 and XPF expression (data not shown). The TNM stage was available for all 24 samples analyzed and included $11 \mathrm{~T} 1$ and 13 T2. Data analysis revealed no correlation between tumor stage and expression level of ERCC1 and XPF (data not shown). Finally, we analyzed whether the expression of ERCC1 correlates with the expression of XPF in the tumor tissues. We found a clear correlation between the expression levels of ERCC1 and XPF in the tumor samples (Fig. 5).

\section{Discussion}

In this study we found a significant difference in the levels of ERCC1 and XPF proteins in non-seminoma versus seminoma testis tumor tissue. ERCC1 associates with XPF to form a structure-specific endonuclease that operates in NER. The ERCC1-XPF complex executes the incision in the DNA strand 5' of the DNA damage through an intrinsic endonuclease activity of XPF (13). Mammalian cells with inactivating mutations in either the ERCC1 or XPF gene manifest impaired NER and consequently increased sensitivity towards DNA damaging drugs such as cisplatin (25). On the other hand, there is increasing evidence that increased NER repair activity in tumor cells is linked with therapeutic resistance against cisplatin chemotherapy. Several investigations have examined the expression of NER mRNA and proteins in human cancer tissues. Attention has notably been payed to ERCC1, the first human DNA repair gene cloned. In gastric carcinoma, elevated ERCC1 mRNA levels were suggested to be associated with cisplatin resistance (19). In tissue samples from patients with colorectal cancer, ovarian cancer or nonsmall cell lung cancer (NSCLC) low expression of ERCC1 mRNA was found to be associated with a good response to chemotherapy $(17,18,20)$. Equally a low level of ERCC1 protein in lung cancer tissue was associated with longer patient survival after cisplatin-based chemotherapy (15). Therefore, it was proposed that the level of ERCC1 protein might serve as a powerful predictor of response to cisplatinbased chemotherapy and clinical outcome.

Although cisplatin is the gold standard in the therapy of TGCT, scarce information is available regarding the expression of DNA repair proteins in testis tumor tissue. In one single study the level of XPA protein was investigated in a series of testicular seminomas and spermatocytic seminomas. No XPA protein could be detected in the seminoma tissues while all spermatocytic seminomas were positive for the protein suggesting that spermatocytic seminomas originate from a later stage of germ cell development than seminomas (26). For ERCC1 and XPF we show here that testis tumor tissue expresses a higher level of ERCC1 and XPF compared to the corresponding normal tissue of the same patient. This abundance is characteristic for nonseminomas as seminomas display no significant difference in ERCC1 and XPF level compared with normal testis. TGCT originate from germ cells and have a common progenitor lesion, the carcinoma in situ, in which a series of cytogenetic and molecular alterations lead to the transformation into seminoma (5). Seminoma may subsequently develop into non-seminoma, which are more aggressively growing and have a high tendency for metastasis (27). Our data indicate that the progression of seminoma to non-seminoma may go along with increased expression of ERCC1-XPF. Of note, we could not find a significant correlation between the expression of ERCC1 and XPF and clinical parameters such as TNM stage of non-seminomas. Although the mechanisms of upregulation is unknown, the data suggest that ERCC1 and $\mathrm{XPF}$ is co-regulated in the tumor tissue presumably by stabilization due to protein-protein interaction $(28,29)$. It is noteworthy that another repair protein, Fen1, was found to be up-regulated in TGCT (30), whereas the $\mathrm{O}^{6}$-methylguanineDNA methyltransferase (MGMT) repairing $\mathrm{O}^{6}$-alkylguanine adducts was found to be down-regulated (31). Therefore, the data are not in line with the supposition of a general upregulation of DNA repair genes in TGCT. Since ERCC1$\mathrm{XPF}$ is involved in the repair of cisplatin-induced DNA adducts one may anticipate that non-seminomas are resistant to cisplatin. This, however, is not the case in view of the good curability of these cancers. Therefore, it is possible that other tumors that do not respond to cisplatin-based therapy display even higher levels of ERCC1-XPF. Alternatively, one may suppose that TGCT execute very effectively the cisplatin-triggered cell death program. Work is in progress to prove these lines of arguments.

\section{Acknowledgements}

We thank Heike Dürk and Georg Nagel for technical assistance. This study was supported by DFG-KO 1732/1-1. 


\section{References}

1. Bosl GJ and Motzer RJ: Testicular germ-cell cancer. N Engl J Med 337: 242-253, 1997.

2. Horwich A, Shipley J and Huddart R: Testicular germ-cell cancer. Lancet 367: 754-765, 2006.

3. Oosterhuis JW and Looijenga LH: Testicular germ cell tumours in a broader perspective. Nat Rev Cancer 5: 210-223, 2005

4. Di Pietro A, De Vries EGE, Gietema JA, Spierings DCJ and De Jong S: Testicular germ cell tumours: the paradigm of chemosensitive solid tumours. Int J Biochem Cell Biol 37: 2437-2456, 2005.

5. Honecker F, Oosterhuis JW, Mayer F, Hartmann JT, Bokemeyer C and Looijenga LH: New insights into the pathology and molecular biology of human germ cell tumors World J Urol 22: 15-24, 2004.

6. Jones RH and Vasey PA: New directions in testicular cancer; molecular determinants of oncogenesis and treatment success. Eur J Cancer 39: 147-156, 2003.

7. Feldman DR, Bosl GJ, Sheinfeld J and Motzer RJ: Medical treatment of advanced testicular cancer. JAMA 299: 672-684, 2008.

8. Rabik CA and Dolan ME: Molecular mechanisms of resistance and toxicity associated with platinating agents. Cancer Treat Rev 33: 9-23, 2007.

9. Masters JR and Köberle B: Curing metastatic cancer: lessons from testicular germ-cell tumours. Nature Rev Cancer 3: 517-525, 2003.

10. Kartalou M and Essigmann JM: Mechanisms of resistance to cisplatin. Mutat Res 478: 23-43, 2001

11. Gillet LC and Schärer OD: Molecular mechanisms of mammalian global genome nucleotide excision repair. Chem Rev 106: 253-276, 2006

12. McHugh PJ, Spanswick VJ and Hartley JA: Repair of DNA interstrand crosslinks: molecular mechanisms and clinical relevance. Lancet Oncol 2: 483-490, 2001.

13. Sijbers AM, De Laat WL, Ariza RR, et al: Xeroderma pigmentosum group $\mathrm{F}$ caused by a defect in a structure-specific DNA repair endonuclease. Cell 86: 811-822, 1996.

14. Niedernhofer LJ, Odijk H, Budzowska M, et al: The structurespecific endonuclease Ercc1-Xpf is required to resolve DNA interstrand cross-link-induced double-strand breaks. Mol Cell Biol 24: 5776-5787, 2004.

15. Olaussen KA, Dunant A, Fouret P, et al: DNA repair by ERCC1 in non-small cell lung cancer and cisplatin-based adjuvant chemotherapy. N Engl J Med 355: 983-991, 2006.

16. Jun HJ, Ahn MJ, Kim HS, et al: ERCC1 expression as a predictive marker of squamous cell carcinoma of the head and neck treated with cisplatin-based concurrent chemotherapy. Br J Cancer 99: 167-172, 2008.

17. Dabholkar M, Bostick-Bruton F, Weber C, Bohr VA, Egwuagu C and Reed E: ERCC1 and ERCC2 expression in malignant tissues from ovarian cancer patients. J Natl Cancer Inst 84: 1512-1517, 1992.
18. Dabholkar M, Vionnet J, Bostick-Bruton F, Yu JJ and Reed E: Messenger RNA levels of XPAC and ERCC1 in ovarian cancer tissue correlate with response to platinum-based chemotherapy. J Clin Invest 94: 703-708, 1994.

19. Metzger R, Leichman CG, Danenberg KD, et al: ERCC1 mRNA levels complement thymidylate synthase mRNA levels in predicting response and survival for gastric cancer patients receiving combination cisplatin and fluorouracil chemotherapy. J Clin Oncol 16: 309-316, 1998.

20. Lord RV, Brabender J, Gandara D, et al: Low ERCC1 expression correlates with prolonged survival after cisplatin plus gemcitabine chemotherapy in non-small cell lung cancer. Clin Cancer Res 8: 2286-2291, 2002.

21. Welsh C, Day R, McGurk C, Masters JR, Wood RD and Köberle B: Reduced levels of XPA, ERCC1 and XPF DNA repair proteins in testis tumor cell lines. Int J Cancer 110: 352-361, 2004.

22. Bronson DL, Andrews PW, Solter D, Cervenka J, Lange PH and Fraley EE: Cell line derived from a metastasis of a human testicular germ cell tumor. Cancer Res 40: 2500-2506, 1980.

23. Bubenik J, Baresova M, Viklicky V, Jakoubkova J, Sainerova H and Donner J: Established cell line of urinary bladder carcinoma (T24) containing tumour-specific antigen. Int J Cancer 11: 765-773, 1973.

24. Köberle B, Masters JR, Hartley JA and Wood RD: Defective repair of cisplatin-induced DNA damage caused by reduced XPA protein in testicular germ cell tumours. Curr Biol 9: 273-276, 1999.

25. Sijbers AM, Vader PCV, Snoek JW, Raams A, Jaspers NGJ and Kleijer WJ: Homozygous r788w point mutation in the xpf gene of a patient with xeroderma-pigmentosum and late-onset neurologic disease. J Invest Dermatol 110: 832-836, 1998.

26. Stoop H, van Gurp R, De Krijger R, et al: Reactivity of germ cell maturation stage-specific markers in spermatocytic seminoma: diagnostic and etiological implications. Lab Invest 81: 919-928, 2001.

27. Honorio S, Agathanggelou A, Wernert N, Rothe M, Maher ER and Latif F: Frequent epigenetic inactivation of the RASSF1A tumour suppressor gene in testicular tumours and distinct methylation profiles of seminoma and non-seminoma testicular germ cell tumour. Oncogene 22: 461-466, 2003.

28. Yagi T, Wood RD and Takebe H: A low content of ERCC1 and a $120-\mathrm{kDa}$ protein is a frequent feature of group $\mathrm{F}$ xeroderma pigmentosum fibroblast cells. Mutagenesis 12: 41-44, 1997.

29. Biggerstaff M, Szymkowski DE and Wood RD: Co-correction of the ERCC1, ERCC4 and xeroderma pigmentosum group F DNA repair defects in vitro. EMBO J 12: 3685-3692, 1993.

30. Nikolova T, Christmann M and Kaina B: FEN1 is overexpressed in testis, lung and brain tumors. Anticancer Res 29: 2453-2459, 2009.

31. Nagel G, Brenner W, Johnsson K and Kaina B: DNA repair protein O6-methylguanine-DNA methyltransferase in testis and testicular tumors as determined by a novel non-radioactive assay. Analyt Biochem 321: 38-43, 2003. 